\title{
Navigating the policy stream: Contested solutions and organizational strategies of policy entrepreneurship
}

Livia Johannesson and Martin Qvist

\section{(2) OpenEdition}

\section{Journals}

Electronic version

URL: http://journals.openedition.org/irpp/740

DOI: $10.4000 /$ irpp.740

ISSN: 2706-6274

\section{Publisher}

International Public Policy Association

\section{Printed version}

Date of publication: 27 April 2020

Number of pages: 5-23

ISSN: 2679-3873

\section{Electronic reference}

Livia Johannesson and Martin Qvist, « Navigating the policy stream: Contested solutions and organizational strategies of policy entrepreneurship », International Review of Public Policy [Online], 2:1 | 2020, Online since 27 April 2020, connection on 11 June 2020. URL : http://journals.openedition.org/ irpp/740 ; DOI : https://doi.org/10.4000/irpp.740

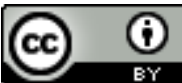

International Review of Public Policy is licensed under a Creative Commons Attribution 4.0 International. 


\section{Navigating the policy stream: Contested solutions and organizational strategies of policy entrepreneurship}

\section{Livia Johannesson}

Stockholm Center for Organizational Research, Stockholm University

\section{Martin Qvist}

Department of Political Science, Stockholm University

\section{Abstract}

In the Multiple Streams Framework (MSF), policy entrepreneurs are primarily defined by their ability to promote and seek support for policy solutions. Recent research, however, points to the importance of policy entrepreneurs as "arena shapers" who attempt to create favorable conditions for their solutions in conflictual policy settings. In this paper, we seek to incorporate such strategies into the MSF by drawing on the organizational foundations of the original garbage can model. The main question is what role do policy entrepreneurs play in "organizing out" opposition from pre-decision processes, as a way of advancing contested policy solutions. We answer this question in a case study of a controversial hospital "mega-project" in Stockholm healthcare that shows how a small but influential team of entrepreneurs used the project as an opportunity for policy change. The study helps to identify three different organizational strategies: 1) regulating participation in order to neutralize opponents: 2) specializing attention to limit the "searchlight" and 3) sequential attention in order to reduce complexity and build commitment. While effective for advancing solutions in the face of conflict and entrenched positions, organizational strategies also have important democratic implications for the legitimacy of pre-decision processes and the prospects for broad deliberation.

\section{Keywords}

multiple streams framework, policy entrepreneurs, garbage can, organizational strategies, mega-project 


\section{Introduction}

How, and under what conditions, contested solutions become viable political alternatives have been key questions in the literature on agenda-setting in public policymaking (Kingdon 1984; Keeler 1993; Baumgartner \& Jones 1993; Zahariadis 2003; Zohlnhöfer \& Rüb 2016). Researchers often find that policy entrepreneurs play a vital role in these processes by preparing and refining solutions and by promoting them when opportunities appear (see, e.g., Mintrom \& Norman 2009; Guldbrandsson \& Fossum 2009; Meijerink \& Huitema 2010; Oborn, Barrett \& Exworthy 2011; Spohr 2016; Saetren 2016a). In John Kingdon's (1984) original formulation of the Multiple Streams Framework (MSF), proposals rise to prominence in a gradual process of "softening up" and "emerging consensus" within policy communities. Later research has developed this understanding, emphasizing that the character of policy communities and the ways they generate alternatives can vary significantly between different policy settings (Zahariadis 2003; Herweg 2016). Policymaking is increasingly characterized by complex problems and knowledge claims that are contested and politicized (e.g. Wolf \& Van Dooren 2017; Griggs \& Howarth 2018; Daviter 2019). Therefore, policy entrepreneurs sometimes find themselves in situations where they face resistance and competition from other teams of entrepreneurs (Mintrom 2013; Cohen 2016; Brouwer \& Biermann 2011; Saetren 2016a; Reimer \& Saerbeck 2017).

One key question in such oppositional contexts is the extent to which policy entrepreneurs not only develop, and seek attention for, their solutions but also apply strategies for maneuvering out rival solutions and "opposition players" (Cohen 2016). More specifically, the question we address here is what role policy entrepreneurs play in "organizing out" opposition from pre-decision processes and how such strategies can be incorporated into the multiple streams framework.

Previous research on policy entrepreneurs has pointed to the importance of the "arena strategies" that are sometimes used to manipulate the access structure (Brouwer \& Biermann 2011; Meijerink \& Huitema 2010), with particular emphasis on the significance of coalition building (Mintrom \& Norman 2009; Mintrom 2013) and the role of venue shopping (Baumgartner \& Jones 1993) - seeking out the most favorable conditions for advancing a solution (Brouwer \& Biermann 2011; Cairney 2018). These discussions, however, have only been incorporated with the MSF to a limited degree, a reflection of the fact that the concept of policy entrepreneurs is often used without connecting it to the full framework (Zohlnhöfer, Herweg \& Rüb 2015).

We seek to contribute to the MSF literature by demonstrating how organizational strategies can explain how policy entrepreneurs manage to exclude rival solutions and potent opposition from important arenas as a way of advancing contested policy solutions. Furthermore, we argue that organizational strategies can be incorporated into MSF by reconnecting with the organizational foundations of the original "garbage-can model” (Cohen, March \& Olsen 1972). The concept of organizational strategies combines the garbage-can component of organizational structures - which was not incorporated in Kingdon's (1984) adaptation of the model - and the actor-structure dynamic which he created by introducing the concept of policy entrepreneurs (Saetren 2016b; Zahariadis 2003).

We develop the concept of organizational strategies based on a case study of how a hospital "mega-project" was used to promote a set of highly contested policy ideas in the Stockholm healthcare sector. We demonstrate how a small but influential group of policy entrepreneurs managed to "organize out" opposition in order to advance their package of ideas in the process 
of generating alternatives. We identify three different organizational strategies based on this empirical study: 1) regulating participation in order to neutralize opponents, 2) specializing attention to limit the "searchlight" and 3) sequential attention in order to reduce complexity and build commitment. We conclude with a discussion of conditions under which policy entrepreneurs' organizational strategies can play an important role and we also provide suggestions for further research.

\section{Multiple Streams Framework and policy entrepreneurs' organizational strategies}

The multiple streams framework offers a dynamic approach to policymaking and is more relevant than ever when policymaking is increasingly characterized by complex problems and disagreements between experts about appropriate courses of action (see, e.g., Zohlnhöfer \& Rüb 2016, 3). The framework is still centered around the key concepts that John Kingdon (1984) developed, based on an adaption of the garbage-can model (Cohen et al. 1972). In this framework, agenda-setting is seen as a function of the confluence of three streams - problems, policies and politics - that flow through the political system relatively independent of each other. Alternatives rise to the decision-agenda when "a problem is recognized; a solution is available and the political climate makes the time right for change" (Kingdon 1984, 93). A policy window opens either in the problem stream (for example, when a problem gains policymakers' attention as the result of a crisis) or in the political stream (for example, as a consequence of a change of government). Favorable alignment of the three streams creates a window for change, but the coupling of the streams requires an intervention by policy entrepreneurs - resourceful experts and innovative networkers in the policy community (Kingdon 1984; see also Mintrom \& Norman 2009; Cairney 2018).

Despite the merits of this policy perspective, there is broad agreement among policy scholars that many of the concepts and subcategories of MSF are in need of further theoretical refinement (Zahariadis 2016a). The policy stream, which is our focus here, is no exception (Herweg 2016). In the original version, Kingdon famously compared the development of alternatives within policy communities to a process of natural selection. Kingdon describes an incremental "softening-up" process whereby ideas and proposals are refined and modified in order to gain legitimacy, resulting in an "emerging consensus" among specialists and experts around one, or a few, viable alternatives $(1984,127-29 ; 139)$.

There are, however, cases that do not fit this picture: for instance, situations that involve multiple policy communities with varied and conflictual interests, agendas and values. Both the pace of alternative generation and the development of solutions, in either collaborative or competitive modes, can vary depending on how well integrated the policy community is (Zahariadis 2003). Describing the selection process as a struggle between multiple players corresponds well with later contributions to the literature on policy entrepreneurship, which emphasize that policy entrepreneurs are not merely passively waiting for the right chance to pitch their ideas - they are often active in influencing the policy environment in all three streams (Cairney 2018; see also Oborn et al. 2011). With this in mind, we will discuss the role of policy entrepreneurs in more detail, focusing on strategies of manipulating access and seeking out favorable conditions, identified in previous research.

\section{Policy entrepreneurs and the manipulation of access in the policy stream}

Policy entrepreneurs are defined by their actions, rather than their positions, and thus they can be found in both the public and private sectors, as well as in civil society. They are individuals 
who succeed in influencing policy outcomes without having the formal resources required to achieve these changes on their own (Cohen 2016, 180). Apart from policy entrepreneurs' personal characteristics and attributes, the literature has pointed out a large number of strategies that policy entrepreneurs use to promote their preferred solutions within the policy stream (Frisch Aviram et al., 2019). Many of these strategies can be categorized as attention- and support-seeking activities that they use to promote a particular solution. Widely used strategies include various rhetorical moves, such as the framing of solutions and problems (Zahariadis 2003; Mintrom \& Norman 2009, 661; Aukes et al. 2017; Frisch Aviram et al. 2019) and the strategic use of symbols to create a shared emotional and cognitive understanding of a policy solution (Zahariadis 2003,156).

Of particular interest for our purpose here are coalition and arena strategies, which seek to reduce the influence of the opposition and in some cases actively shape policy arenas and make strategic use of time and place in the policy process (Baumgartner \& Jones 1993; Zahariadis 2003, 156; Meijerink \& Huitema 2010; Brouwer \& Biermann 2011; Reimer \& Saerbeck 2017). Coalition-building strategies have been described as one of the most important tools for successful policy entrepreneurship. Policy entrepreneurs need to build coalitions and form alliances in order to mobilize the strength and resources they need to make their solutions viable (Meijerink and Huitema 2010). Brouwer and Biermann (2011) demonstrate how policy entrepreneurs sometimes opt for broad coalitions when disseminating their ideas, but at other times deliberately form small groups of closed networks in order to exclude unwanted opposition. This indicates that they can influence the access structure within the policy stream. Saetren (2016a) makes a similar point when discussing how policy entrepreneurs, if possessing sufficient power positions, can use "policy design" strategies, which means eliminating the institutionalized process of negotiating policy suggestions by turning an open access structure into a closed process. The purpose of such strategies is "organizing influential adversely affected stakeholders out of the policy formulation process" (Saetren 2016a, 86).

Arena strategies have been identified as one possible way of manipulating time and space within the policy stream (Brouwer \& Biermann 2011). By choosing the places where the "policy game" is played out - venue shopping (Baumgartner \& Jones 1993) - policy entrepreneurs attempt to secure the most favorable conditions for advancing a specific policy solution (Cairney 2018). Meijerink and Huitema (2010), in their study of multiple cases of water policy, highlight that policy entrepreneurs not only exploit existing arenas but also engage in manipulation and the formation of venues in order to create favorable conditions for policy adoption.

Time is another factor which policy entrepreneurs' strategies can manipulate, by either slowing down or speeding up the policy-formulation process. Brouwer and Biermann (2011) mention the strategic use of deadlines to slow down policy processes, and strategic choices of when to include stakeholders, as examples of timing strategies used by policy entrepreneurs in the case of regional water management in the Netherlands. Another strategy aimed at manipulating time is what Zahariadis calls "salami tactics" - policy entrepreneurial activities that "slice" decision-making into distinct stages to enhance the "chances of agreement" in a step-by-step process $(2003,156)$.

Previous research on policy entrepreneurship points to the importance of strategies for manipulating the conditions for advancing a proposal. A recurring component in several studies is the arena-shaping activities of policy entrepreneurs. This component, however, has not yet been fully integrated into the MSF framework and many contributions do not explicitly seek to do so. Some strategies, however, have been developed within the MSF, such as the notions 
of "salami tactics" (Zahariadis 2003) and "policy design" (Saetren 2016a), and will be used to inform our discussion on organizational strategies.

\section{Organizational strategies}

In order to create an approach to arena-shaping strategies that can be fully incorporated into the underlying premises of MSF, we draw on the organizational component of the original garbage-can model. As Saetren argues (2016b; see also Zahariadis 2016b), the concept of organizational structure was lost in Kingdon's adaptation of the model. This was a key concept for adapting the model to different types of institutional contexts (see Olsen 1983). Later applications to public policy emphasize that most decision processes do not display the character of a pure garbage-can process (e.g., March \& Olsen 1976; Olsen 1983). Instead, a key feature of the garbage-can model is the distinction between three types of organizational structures: open structures (with unsegmented access from problems, solutions and participants), specialized structures (where a limited number of participants have legitimate access to the decision arena), and hierarchical structures (where important decision makers have access to more arenas than do less important ones) (Cohen et al. 1972; March 1994).

Including organizational structure in MSF offers a way to conceptualize the often segmented and highly specialized nature of decision arenas in political systems (Saetren 2016b). As Schattschneider argues (1975), political organization reflects the exercise of power through the allocation of attention in a political system: some conflicts are exploited, while others are suppressed by being kept off the agenda. In a corporatist system, for instance, decision-making occurs in a specialized structure where only certain organized interests have legitimate access (Olsen 1983; see also Spohr 2016). This arrangement privileges the conflict between labor and capital and at the same time "organizes out" issues related to other types of conflicts.

A significant advantage of MSF over the garbage-can model is that the MSF framework offers an important actor-structure dynamic in the role of policy entrepreneurs. This facilitates the analyzing of organization not just as a structural property but also in terms of organizational strategies (Weick 1979). Hence, the concept of organizational strategies combines the organizational component of the garbage-can model with the actor-structure dynamic introduced by MSF.

While policy entrepreneurs are rarely in a position to alter formal institutional structures, we argue that they can play an important role in organizing and designing preparatory processes and activities. In terms of concrete manifestations of such strategies, policy entrepreneurs can engage in the organization of events, campaigns and study visits, for example; they can form meeting groups and committees and they can gain influence over the design of various bodies for preparatory planning and investigations (see also Kingdon 1984, 122).

It is important to note that organizing, as a stand-alone strategy, is not necessarily connected to policy entrepreneurship. By definition, policy entrepreneurs advance specific solutions. We therefore should expect to find organizing alongside the other strategies mentioned in the literature. It is a strategy that aims at improving the odds of a solution surviving in a context of competition and its criterion for success is the ability to "organize out" rival solutions and potent opposition. From this, it follows that organizing can also be used to influence the pace with which alternatives are generated by creating better-integrated subsets of policy communities (cf. Zahariadis 2003).

Based on this examination of the garbage-can model and its possible application to policy entrepreneurial strategies, the empirical part of this paper seeks: 1 ) to determine the type of 
organizational structures (hierarchical/specialized/open) in which solutions are developed, and 2) to explore how and to what extent this structure is influenced by the actions of policy entrepreneurs.

\section{Case selection and methods}

Focusing on organizational strategies of policy entrepreneurship, we apply MSF to a case of mega-project planning in Sweden - namely, the initiation and preparatory planning of a new university hospital within Stockholm County Council, called Nya Karolinska Solna (NKS). Mega-projects tend to be controversial and therefore represent an interesting class of cases for studying how contested solutions gain prominence in the policy stream. Miller and Lessard (2008, 146-47) describe them as "dynamic, iterative and often chaotic systems" composed of episodes with different dynamics (see also Flyvbjerg 2014). Moreover, mega-projects generally involve a broad range of policy specialists and different sector-specific policy communities and thus solutions are likely to meet resistance from rival teams of entrepreneurs promoting their alternatives.

The NKS project was, from the start, surrounded by controversies and conflicting interests, especially among different segments of the healthcare professions. The process leading up to the formal decision, in 2008, to build a new world-class university hospital began in the late 1990s and, to date, the project has been one of the most publicly debated and widely criticized decisions in the history of Stockholm healthcare. The building was completed in 2016 and the hospital is now in operation. However, the implications of the whole policy package that accompanied the construction of the new hospital are profound and will have consequences for the organization of Stockholm healthcare for many years to come. The pre-decision process of the NKS case can therefore be described as existing within a conflictual policy setting with many powerful, and oppositional, actors.

The case-study approach is motivated by the aim of developing a more in-depth understanding of organizational strategies of policy entrepreneurship rather than testing previous propositions (Gerring 2004). Our case is theoretically relevant to this aim because policy entrepreneurs were directly involved in organizing the pre-decision phase. This was possible because of several intervening conditions. First, this case concerns sub-national level policymaking, where there are often, at least in Sweden, more opportunities to adapt the organizational arrangements for pre-decision processes situationally compared with national-level decisions. Second, the extraordinary nature of mega-projects often involves ways of organizing the preparatory processes and procedures that are not standardized (Flyvbjerg 2014).

\section{Methods and material}

This case study builds on a qualitative analysis aimed at reconstructing the processes within the policy stream, from the initiation of the project around the turn of the millennium until Stockholm County Council made the formal decision to build the hospital in April 2008.

The empirical material consists of policy documents (reports, decisions, protocols from assembly debates, statements, missions, proposals and letters found in the archives of SCC) and interviews with key actors in the early stages of the NKS project. A document analysis reconstructed the formal process and provided information about the key actors, including policy entrepreneurs, and the organizational setting for the process. Interviewees were selected through a combination of purposive and snowball sampling techniques. Apart from a few central politicians who had passed away, or were unreachable for other reasons, we received ac- 
cess to all the people we had identified as key actors. We also asked each interviewee who they considered to be the most significant actors in the agenda-setting phase of the NKS process. This double sampling strategy enabled us to verify and correct our initial list of interviewees during the course of data collection. Additionally, we were able to include people who were formally responsible for early planning in the process and also individuals who were part of the "hidden clusters of specialists" (Kingdon 1984, 68) and who therefore affected the NKS decision-making process in informal ways.

Ultimately, 18 semi-structured interviews were conducted with high-level Stockholm County Council civil servants and politicians, representatives of the Karolinska Institute (KI) medical university and representatives of the medical profession at the old Karolinska University Hospital. Most of the interviewees had retired from these positions by the time of the interview. Each interview lasted between one and two hours and was guided by themes rather than predetermined questionnaires, since the questions needed to be tailored to fit the competence and experience of each interviewee. We asked about the rationales and ideas behind the initiation of the project, which organizational stages the project went through in its transformation from visionary ideas to concrete decision and what challenges and difficulties the involved actors, in their respective roles and positions, faced during this process. We corroborated the information we received from interviews against other interview accounts, as well as against available documents. We also paid attention to whether interviewees described first-hand experiences or not and whether they might have reasons to present a biased picture of their own or other actors' roles in the process (Morris 2009). The analysis of the transcribed interviews and the policy documents made full use of the MSF. The coding scheme was set up around the three streams and also included a chronological categorization that allowed for analysis of developments within each stream over time. However, this paper focuses particularly on the role of the policy entrepreneurs in organizing the policy stream.

Policy entrepreneurs were coded as an actor category in the policy stream and these actors were connected to the policy solutions and entrepreneurial strategies during the coding process. Through this we could understand which entrepreneurs promoted which particular ideas and how they linked complementary ideas to each other, as well as how they framed problems to fit the ideas. Drawing on discussions by Saetren (2016b) and Zahariadis (2016a; 2016b) on the roles of institutional and organizational structure in MSF, organizing was added as a separate coding category in the analysis of policy entrepreneurial strategies. This means that, from the outset, organizing was not connected to the actor category of policy entrepreneurs. This connection instead emerged during the course of analyzing the empirical material. This category was further refined in order to differentiate between different types of organizational strategy, using a fairly simple inclusion/exclusion dichotomy. It was also coded for participants' access to different venues and arenas, as well as for what problems and solutions were included in the set-up of an investigation or were put up for discussion in committees. We also considered the timing of inclusion/exclusion, as well as how and when policy suggestions were presented to policymakers. Together, this coding strategy resulted in the three different organizational strategies we present here in the case-study analysis.

\section{The NKS pre-decision process: Case description}

Sweden is divided into regions, with Stockholm County Council (SCC) being the largest region in terms of population and tax resources. As with all county councils, SCC is composed of an elected council assembly (Landstingsfullmäktige), a formal executive committee (Landstingssty- 
relsen) headed by the executive member for finance and an administrative organization headed by the administrative director. In Sweden, county councils (and municipalities) have relatively broad autonomy from the national government to make their own budgets and to decide on local tax levels. The municipalities are responsible for a wide range of welfare services, while the county councils' primary responsibility is healthcare. The national and local political systems are similarly organized in terms of proportional representation and collective decision-making and the same political parties dominate at both national and local levels.

Before turning to the analysis of policy entrepreneurs' strategies, we provide a brief overview of the pre-decision process in the NKS case, which involved a large number of preparatory activities and produced a number of reports. The key phases and events leading up to the decision in 2008 can be summarized as follows:

- Report on renovation costs - a problem window for policy change (May 2000)

- Initiation of preparatory investigations (November 2001)

- Initial inquiry - developing the concept of NKS (2001-2002)

- Second inquiry - restructuring the healthcare system (2003-2004)

- Competition among architectural firms on conceptual design (2005-2006)

- Formal decision to build a new hospital (April 2008)

At the beginning of the new millennium the old Karolinska University Hospital, located in the northern part of Stockholm, was in need of substantial renovation. The main hospital building had been completed in 1940 and the other hospital buildings were all more than 50 years old. SCC's property-management company conducted an investigation into the renovation needs and in May 2000 it presented calculations on the aggregated renovation costs (Locum 2002, 4). These calculations immediately caught the policymakers' interest as they presented the renovation costs as comparable with the costs of building a new hospital (IP6, IP8, IP5). While the renovation needs had been known for a long time, they had not been presented in this way and this suddenly opened up a policy window in the problem stream.

This coupling of problem and politics meant that the possibility of a major hospital reform rose on the agenda; however, there was not yet a worked-out proposal to attach to the problem, other than the renovation plans which senior management at the old Karolinska Hospital continued to develop (Karolinska Hospital 2002). This renovation proposition, however, was not in line with the type of reform that policymakers had in mind. Instead, some influential actors from the medical university of Karolinska Institute (KI) put forth a conceptual idea of building a smaller, research-intensive university hospital that could offer highly specialized and internationally competitive care in a global healthcare market. This idea was picked up by the executive member for finance, conservative politician Ralph Lédel, who in November 2001 sent a letter to the SCC executive committee, suggesting that it investigate the possibility of building a new university hospital close to the KI (SCC, 2001). At this time, a team of dedicated policy entrepreneurs was assigned to the process and refined the original idea into an ambitious reform package.

This team of entrepreneurs was tasked with conducting an initial inquiry to investigate the possibility of developing the conceptual idea in more detail. A year later, in November 2002, the final report from the investigatory committee confirmed that the best option would be to build a new university hospital, following the same conceptual vision as that suggested by the executive member of finance (SCC 2002). 
Around the time that this report was completed, the conservative alliance lost the SCC elections and a social democratic-led political majority took control. However, this change in the political stream was not decisive for the future of the NKS project. On this issue, the political conditions have been characterized by stability. In fact, there was a stable consensus among all the political parties regarding the concept of building a new, smaller, research-intensive hospital during the whole period between 2001 and 2008. It was only after the decision was made to build the new hospital that conflict erupted between the political parties; however, this conflict centered around the choice of financing model and not the project per se.

The second inquiry, initiated in 2002, focused on the consequences of building a smaller and more specialized hospital for the healthcare system in Stockholm. At this stage the hospital became part of a larger reform package, which was needed to demonstrate that a downsized hospital was technically feasible and that its consequences were acceptable in terms of providing adequate access to healthcare for the citizens of Stockholm.

The technical aspects of the proposal were also developed through a design contest from 2005 to 2006, in which selected architectural firms were invited to develop suggestions for the hospital's conceptual design. Politicians had not previously taken a hands-on role in the process, but at this point they became more actively involved. Leading politicians were part of the contest jury and the winning proposal was decided by a unanimous vote (SCC 2006).

The process became more formally organized in late 2006 with the installation of a special NKS program office. At this point, the focus was solely on developing and refining the NKS proposal to the point where it was ready to be presented to the SCC assembly for decision. It was subsequently adopted in April 2008, with near full agreement between all the political parties (SCC 2008).

\section{Policy entrepreneurs' organizational strategies}

In order to answer our research question about the role that policy entrepreneurs play in "organizing out" opposition from pre-decision processes, we divide our analysis into three parts. First, we show how policy entrepreneurs use well-known strategies, such as framing, teambuilding and combining ideas into the reform package that became NKS. Second, we analyze the organizational structure of the pre-decision process and conclude that it constitutes a specialized structure, which has implications in terms of the inclusion and exclusion of actors, problems and solutions. Third, we demonstrate that policy entrepreneurs were able to shape this specialized structure and identify three different strategies that they used in the NKS case.

\section{Combining ideas and framing the solution}

Policy entrepreneurs played a very pronounced role in creating and promoting the NKS project so that it became the "winning" solution. A handful of specialists representing different but closely related policy ideas formed a well-integrated team (cf. Mintrom \& Norman 2009) that combined these ideas into a single solution - a new, downsized, research-intensive university hospital specializing in advanced medical treatment. The ideas in themselves were not unique - they reflected broad trends in the international field of healthcare management — and had long been discussed among healthcare specialists, academics, bureaucrats and politicians in and around the SCC. The ideas that together formed the basis for the solution are summarized as follows: ${ }^{1}$

1 - In addition to these four reform ideas, the NKS also became an opportunity to test a Public Private Partnership (PPP) model for the financing of the new hospital (which has later been subject to heated debate and widespread criticism over cost escalations). The decision-making on this financing model was a parallel process in the planning of the NKS, which will not be covered in the present paper. 
1) Promoting Centers of Excellence. This idea reflected the trend in research policy around the turn of the millennium towards emphasizing competition and performance-based funding and promoting strong research environments (e.g. Hallonsten \& Silander 2012). The policy entrepreneurs saw an opportunity to use the Nobel Prize — which is intimately associated with the KI - as a powerful symbol for advancing the idea of a researchintensive hospital near the medical university.

2) Innovation and economic growth. With inspiration from "triple helix" thinking about collaboration between academia, industry and government (e.g. Ranga \& Etzkowitz 2013), Stockholm had, by the beginning of the millennium, started to brand itself as a hub for life-sciences research and industry. A new and modern top-tier university hospital would further the goal of creating an internationally competitive life-sciences cluster in the northern part of the city, forming a new city district with residential and commercial development.

3) Healthcare restructuring. As a consequence of increased specialization, increasingly advanced treatments and technological progress, the cost of highly specialized healthcare increases. Responding to this development, the NKS was used as a means of realizing the idea of an increasingly stratified healthcare system, organized as a pyramid whereby the most expensive and resource-demanding treatments would be delivered from the most specialized hospitals and less specialized treatment could be delivered in less costly facilities such as community hospitals or health centers.

4) Network organization. The new university hospital was meant to pave the way for the gradual introduction of a patient-centered model of hospital organization, altering the traditional clinic structure into a theme-based network structure. The idea of the university hospital as a hub in a larger healthcare network, with strong integration between research and healthcare, drew inspiration from top-ranked role-model hospitals such as the Cleveland Clinic and the Johns Hopkins Hospital in Baltimore, United States.

When the possibility of a grand hospital project debuted around the turn of the millennium, the most important policy entrepreneur was the president of KI. Although he did not have a formal position to influence the SCC agenda, he was widely seen as the prime visionary behind the NKS project, especially the reform ideas of research excellence and innovation and economic growth (IP1; IP12; IP13; IP14; IP3). His vision was to create a dynamic and competitive life-sciences cluster in the area surrounding the KI medical university. At the time, he and some colleagues had a worked-out proposition for this life-sciences initiative, which they pitched in different political forums. They were well connected to high-ranking officials and politicians and were successful in framing their solution in relation to the problem of Swedish medical research lagging in international research rankings (IP4; IP13). At this early stage, the NKS was only a conceptual idea of building a top-class hospital with a strong focus on research near the KI campus - one that would be smaller, in terms of hospital beds, compared with the existing university hospital. It was this idea that the executive member of finance presented in his letter to the SCC executive committee, but although this concept was sufficient to create some momentum, it was far from being a worked-out proposition.

The politicians did not take a hands-on role at this point and instead applied a strategy of appointing and engaging the right people to develop this conceptual idea into a proposal (IP13). In addition to the KI president, who took on a consulting role, a couple of director-level SCC civil servants, who were strong proponents of healthcare restructuring, were appointed to this 
investigation (IP3; IP8). Another important policy entrepreneur appointed to the group was a medical advisor who was an advocate of network organization. In practice, although not formally, the group was led by this medical advisor, who was described by others in our interviews as one of the most persuasive actors in this process (IP8, IP11). Also connected to the group was a professor from KI who, together with the KI president, promoted the idea of research excellence. He was also widely viewed as a policy entrepreneur for network organization (IP1; IP4; IP6; IP9).

The KI president, the medical adviser, the KI professor and the SCC directors can all be seen as policy entrepreneurs in the way that they were active advocates and developers of the main ideas behind NKS. They promoted these ideas long before the NKS project took shape, but they also became involved in one way or another in the process. They were not mandated to make any decisive formal decisions, but they did have considerable leeway in influencing the organizational structure of preparatory planning. While they were each connected to different reform ideas, they worked as a team to develop the whole reform package and were collectively involved in organizing activities. The KI president, however, was mainly active in framing the vision and his role diminished in later parts of the process following his retirement as head of $\mathrm{KI}$ in 2003.

\section{The organizational structure of the pre-decision process}

Although the NKS was founded on ideas that were connected to broad policy trends, the ideas were still highly controversial in the context of Stockholm healthcare. Most notably, the questions about healthcare restructuring and network organization were highly contested within the healthcare community (IP11). Furthermore, the idea of a highly specialized research hospital stood in contrast to the views of specialists who emphasized the importance of catering for the needs of the broader Stockholm population: for instance, by expanding the provision of acute care in the region (IP7).

The idea of innovation and growth was not controversial in itself but could have led to a conflict between different municipalities in the Stockholm area - each of which had its own group of specialists - over where the hospital should be located. There were other potential candidates for locating a "crown" hospital, such as the university hospital in Huddinge, south of Stockholm. Some municipalities in the Stockholm area approached the SCC asking for their own municipality to be a potential site for the new hospital (IP1; IP5; IP6; IP7).

In practice, however, these potential conflicts were never allowed fully to develop during the pre-decision process. In order to understand why, we must look at the organizational structure within which the first initiatives and preparatory activities took place. We would expect that the organizational structure of a process might change over time and, in particular, that it might assume a more formal and hierarchical structure the closer it comes to the formal decision (Zohlnhöfer et al. 2015). Our main focus here, however, is the developments in the policy community at the time that the proposal emerged on to the agenda and was still in the process of becoming a viable solution.

In a hierarchical structure, only high-ranked actors can participate in the process. Problems are hierarchically ordered so that only important problems have access to the significant arenas (Cohen et al. 1972). As Olsen argues (1983, 32), a hierarchical structure in policymaking is characterized by a concentration of power within a legislature. Transferred to our case, we would expect politicians taking a hands-on role and a process that was retained close to the political center. For policy entrepreneurs to be able to create or influence such a structure, they 
would most likely have to be high-ranking politicians or senior members of the core executive. The case of the NKS did not display such characteristics of a politically run process. Instead, its early stages were characterized by considerable discretion and the use of ad-hoc organizational arrangements that operated at arm's length from the political level and were largely separate from the permanent offices of the SCC administration as well. It was not until the design contest that the politicians became more actively involved.

An open structure, on the other hand, is characterized by unsegmented access for participants, solutions and problems (Cohen et al. 1972). If the early stages of the process had been characterized as open, we would expect that latent conflicts around geographical location and ongoing debates between specialists on healthcare restructuring would have been played out within the arenas of preparatory planning. One likely scenario would have been that different solutions would have been articulated, rivalling the one originally presented by the KI president and subsequently developed by the team of entrepreneurs. This, however, only happened to a limited degree. While there were parts of the process that were relatively open to different participants, especially the second inquiry of 2003-2004, this relative openness was coupled with a very restrictive access structure regarding which problems were legitimate subjects of debate. The second inquiry focused solely on problems that might emerge from building a hospital smaller than the existing one and the consequences of this alternative for the Stockholm healthcare system as a whole.

While it is difficult to speculate about solutions that never had the chance to develop fully, a better indication of how rival solutions were "organized out" comes from looking at the one that actually became a potent rival. This alternative was developed by the management of the old Karolinska University Hospital, together with the construction company at the SCC, Locum (IP5, IP6; IP9). This option consisted of a worked-out proposition for an ambitious reconstruction of the existing stock of hospital buildings (Karolinska Hospital 2002; Locum 2002). The old Karolinska University Hospital's proposal was well developed and integrated with dominant reform trends, such as flexibility and network organizing, and therefore had the potential to mobilize parts of the healthcare community and possibly gain prominence in the policy stream. The management of the old Karolinska University Hospital, however, was deliberately kept outside the preparatory planning for the NKS. The policy entrepreneurs, and others within the SCC, perceived the medical professions inside the old Karolinska University Hospital to be both difficult to control and reluctant to embrace change (IP3; IP5; IP8; IP13; IP14). Even in the more open parts of the process, where staff from the Karolinska University Hospital were invited to participate, such participation was on the basis of their specialties and not on the basis of their being representatives of the hospital or specific clinics (IP1).

The way that access was constrained within the second inquiry fits the characteristics of a specialized structure, where a specific arena is devoted to only one or a few problems and where participation is organized into a segmented structure (Cohen et al. 1972): for instance, in the form of subprojects where participants work on different subsets of a topic. Just as in an organization, segmenting preparatory activities around specific purposes and restricting access for participants facilitates action and reduces the risks of conflict or of arenas becoming overloaded with problems and solutions (Olsen 1983, 183; Salet et al. 2013).

Hence, we conclude that the pre-decision process for the NKS best approximates a specialized structure, although the degree of segmentation varied across the different stages of the process. In this case, the structure was not a given at the outset and was instead largely shaped to support the development of the policy entrepreneurs' package of ideas. The organizational 
strategies that the policy entrepreneurs applied to achieve a specialized structure will be described in detail in the next section.

\section{Regulating participation, neutralizing opposition}

Both in the first, exclusive inquiry and in the more inclusive second inquiry, the team of policy entrepreneurs played a key role in shaping the organizations that were established to conduct the preparatory planning activities. In these parts of the process, one key organizational strategy was the strategic manipulation of access for different participants. In the first inquiry, the entrepreneurs wrote the report and input from other specialists - including actors with diverging views - was primarily collected through interviews (IP1; SCC 2002). A more open process - for example, broad participatory seminars and collaborative dialogues inviting participation across healthcare communities - would probably have benefited the main rival solution developed by the management of the old Karolinska University Hospital, since it was better developed in terms of its financial calculations and detailed technical plans for renovation of the existing facilities. This alternative proposal would also likely have been more firmly anchored within the healthcare professions at the old Karolinska University Hospital, since it was less radical in its ambitions to change staff working conditions. At the very least, a more open access structure would have given opponents of the radical NKS agenda the opportunity to slow down the pace at which the alternative was refined (Zahariadis 2003, 46-47). Policy entrepreneurs regulated participation as a means of isolating their main opponents, thereby reducing their ability to mobilize other stakeholders (cf. Schattschneider 1975). While this strategy was not without problems, in terms of gaining widespread support and legitimacy for the project in the longer run, it effectively neutralized the rival solutions - among which the old Karolinska proposal was the most potent - at an early stage. The group swiftly managed to put together a short report which confirmed the need for a small, highly specialized hospital and showed that it could be technically feasible to locate it close to the KI campus (SCC 2002).

This strategy of influencing access to the important arenas for these early preparatory initiatives meant that only selected parts of the policy community were included, while other parts of the policy stream were effectively dammed off. The process of consensus building was then facilitated within these selected segments of specialists. A key enabling factor for the policy entrepreneurs to be able to exert this type of influence was their repeated use of ad-hoc organizational arrangements.

\section{Specialization of attention: Limiting the searchlight}

In addition to the strategic inclusion and exclusion of different actors, organizing also sought a specialization of attention (Cyert \& March 1963; March \& Olsen 1976). The organizing of events, working groups, workshops and other planning activities served as a means of reducing the number of problems and solutions to which policymakers gave their attention at different stages of the process. One important example of this strategy was the organization of a large number of study visits to leading role-model hospitals and research centers around the world, mainly between 2000 and 2004 (SCC 2004). The policy entrepreneurs were the main organizers of these visits. The KI professor and the medical advisor took on the role of "tour guides" for groups of leading politicians and senior civil servants, using their wide international networks in the medical community to open doors (IP1; IP12). By influencing not only which hospitals to visit but also the focus of the visits (for example, patient-centered care or collaboration between hospitals and medical research centers), these visits directed attention and limited the search for other types of solutions. Thus, this became an effective organizational strategy 
that reduced the number of policy options generated at this early stage (Salet et al. 2013) and avoided "information overload" (De Bruijn \& Leijten 2007).

The policy entrepreneurs also used their role as organizers of workshops, and other meetings where stakeholders and experts were invited, to shape the agenda and purpose of these events. The events were an opportunity to test and refine the NKS proposal, but policy entrepreneurs' power over the agenda also meant that some problems could be organized out of the discussion. One example was the strict focus, in the second inquiry, on the question of the consequences of building a smaller hospital, as described above. Another example was the notable lack of attention to problems of recruiting healthcare personnel, especially nurses, which was a known challenge at the time and which has since become an acute and important problem in Sweden (IP7; IP11).

\section{Sequential attention: reducing complexity and building commitment}

The third organizational strategy identified in the NKS case was sequential attention, which is already a well-known strategy of policy entrepreneurs, known as "salami tactics" in the MSF literature (Zahariadis 2003; see also Hinterleitner 2018). We have opted here to use the term sequential attention from the Carnegie school of organizational theory (e.g. Cyert \& March 1963; March \& Olsen 1976; March 1994; see also Zahariadis 2016b), which formed the basis for the garbage-can model, simply for the purpose of conceptual coherence, given our focus on organizational structure.

Sequential attention is an important mechanism for reducing complexity by attending to one sub-goal or sub-problem at a time (Cyert \& March 1963). In the NKS process, the policy entrepreneurs applied this strategy by influencing the sequencing of the different stages in the pre-decision process. This, in turn, facilitated the translation of the conceptual idea into a fully developed proposal by enhancing its technical feasibility and value acceptability - two key criteria for a solution's survival in the policy stream, according to Kingdon (1984). Rather than focusing on both criteria at the same time, preparatory activities alternated between the two. One important purpose of the first investigation was to confirm that it was technically feasible to erect a building of the size envisioned on a parcel of land on the periphery of the existing Karolinska property, near the KI (SCC 2002). No detailed technical planning was required at this stage; it sufficed merely to conclude that building was possible in order to settle the matter of where in Stockholm the hospital was to be built.

The next stage of the process, resulting in the second investigation, focused on the issue of how to organize the Stockholm healthcare structure and largely concerned the proposal's value acceptability. For the NKS project to be accepted, politicians had to be able to assure the public that access to emergency care would not suffer in replacing the old Karolinska University Hospital with a smaller, highly specialized university hospital. Hence, during this second stage, the NKS project was developed into a larger package of solutions that also involved expanding emergency care at other hospitals and investing in healthcare centers (SCC 2004).

The third stage again turned the focus on to the technical matters of the construction project by the announcement of a design contest between different architecture firms to propose an architectural concept for the hospital. When a winner was announced in this contest, a formalized NKS program office was established with the objective of preparing the NKS project for formal decision-making in the political assembly. With that office in place, attention turned to the internal organization of highly specialized care within the new hospital (SCC 2006). 
Sequential attention was also a way of creating commitment through stepwise adoption (Zahariadis 2003). A key concern for the policy entrepreneurs was to balance the level of detail in the refinement of the proposal. It had to be sufficiently detailed to be placed on the decision agenda, but at the same time they wanted to keep it as general as possible in order to avoid getting into a detailed planning process (IP11; IP18). The latter scenario would have required the involvement of a much larger group of specialists and hence a much more open process. Furthermore, one of the most controversial issues in the project was the question of which medical specialties were to be included within the new hospital. This question was, however, deliberately set aside for the future. The directives for the NKS program office stated that the new hospital would be constructed in as flexible a manner as possible, so that the decision on exactly which treatments would be offered there could be postponed (SCC 2006, 6). The postponing of this decision was justified by arguing that technical progress in healthcare treatments was so rapid that it was impossible to know in advance what treatments would be considered as being highly specialized when the hospital was completed. This strategy also avoided miring the process in controversies over this matter (IP1). Postponing the decision on the detailed planning of the care programs to be offered at the NKS meant that the solution was accepted bit by bit. This strategy fits well with Zahariadis's (2003) discussion of salami tactics as a way of facilitating the adoption of controversial decisions by timing the more controversial aspects so that they occur after decision-makers have already put so much effort, time and prestige into the project that it becomes uncomfortable for them to withdraw.

\section{Concluding discussion}

This paper has developed the concept of organizational strategies to account for policy entrepreneurs' attempts to shape the organizational structure of pre-decision processes in order to "maneuver out" opposition and rival solutions. Together, the three strategies identified in the NKS case restricted participation from the main rival team of entrepreneurs, focused attention within the process so as to favor their own solution and split the process into stages in order to reduce complexity and create commitment. This is an example of how consensus can be actively created, even in the face of conflict and entrenched positions in the wider policy community.

These findings connect to previous research on policy entrepreneurs, which has pointed to the importance of various types of "arena" strategies, including those that aim to shape the venues in which entrepreneurs promote their solutions (Brouwer \& Biermann 2011; Meijerink \& Huitema 2010). In relation to the broader literature on policy entrepreneurs, the concept of organizational strategies can be used to add an organizational dimension to policy entrepreneurship. The main contribution of our approach, however, is to the literature that uses the concept of policy entrepreneurs within the multiple streams framework. Drawing on previous research, which has suggested reconnecting to the original garbage-can model as a way of creating an organizational component in the framework (Saetren 2016b, Zahariadis 2016a), the concept of organizational strategies offers a way to integrate policy entrepreneurs' arena-shaping with the underlying foundations of MSF.

It is likely that the conditions under which policy entrepreneurs' organizational strategies may play an important role will vary considerably between different contexts. The possibility of using ad-hoc and temporary organizational arrangements was a key factor in our case and it must be emphasized that the NKS process was particularly distinguished by such arrangements - something that clearly increases the relevance of this type of strategy in our results. At the same time, when seen as something exceptional - as in the case of a large policy re- 
form - they can become projects which are cut off from regular organizational structures and have their own leaders, staffs and budgets. This is often done with the argument of enhancing efficiency and leverage. Hence, instances of "extraordinary policymaking" (Keeler 1993) may also be opportunities for extraordinary organizational arrangements. In processes more firmly shaped by robust institutional arrangements, such as the passing of laws, the opportunities to manipulate the structure may be more limited. This, however, is also likely to depend on the position of policy entrepreneurs who, in some cases, have been shown to be capable of circumventing the regular institutional process (Saetren 2016a).

The case-study design was useful for identifying specific organizational strategies and for developing a deeper understanding of how they are connected to organizational structure. However, further research is needed in order to develop a more comprehensive understanding of the conditions within which organizational strategies may play an important role in advancing contested solutions. As suggested, institutional factors are likely to be important and there may also be important variations between different levels of policymaking (e.g., between national and sub-national levels), as well as between policy areas and factors related to the characteristics of policy communities.

Lastly, we must emphasize that the notion of policy entrepreneurs' organizational strategies has considerable democratic implications. While the team of entrepreneurs identified in our study acted on a public mandate and within broad frames set by the SCC politicians, the organizational strategies they applied reduced opportunities for stakeholder involvement in the early stages of the process. Such strategies can have consequences for the legitimacy of policy processes and for the prospects of broad deliberation. More generally, this form of exercising influence raises normative concerns about the power that policy entrepreneurs may have in preparatory processes - power which may not always be deployed in the public interest. For policymakers, this calls for efforts to ensure that urgency and prospects of realizing grand visions do not obscure commitment to transparency, accountability and democratic control.

\section{Bibliography}

Aukes, E., Lulofs, K., \& Bressers, H. (2018). Framing Mechanisms: The Interpretive Policy Entrepreneur's Toolbox. Critical Policy Studies, 12(4), 406-427.

Baumgartner, F., \& Jones, B. (1993). Agendas and Instability in American Politics. Chicago, IL: University of Chicago Press.

Brouwer, S., \& Biermann, F. (2011). Towards Adaptive Management: Examining the Strategies of Policy Entrepreneurs in Dutch Water Management. Ecology and Society, 16(4), 5.

Cairney, P. (2018). Three Habits of Successful Policy Entrepreneurs. Policy \& Politics, 46(2), 199-215.

Cyert, R. M., \& March, J. G. (1963). A Behavioral Theory of the Firm. Oxford: Blackwell.

Cohen, M.D., March, J.G. \& Olsen, J.P. (1972). A Garbage Can Model of Organizational Choice. Administrative Science Quarterly, 17(1), 1-25.

Cohen, N. (2016) Policy Entrepreneurs and Agenda setting. In N. Zahariadis (Ed.), Handbook of Public Policy Agenda Setting (pp. 180-199). Cheltenham: Edward Elgar.

Daviter, F. (2019). Policy Analysis in the Face of Complexity: What Kind of Knowledge to Tackle Wicked Problems? Public Policy and Administration, 34(1), 62-83. 
De Bruijn, H., \& Leijten, M. (2007). Megaprojects and contested information. Transportation Planning and Technology, 30(1), 49-69.

Frisch Aviram, N., Cohen, N., \& Beeri, I. (2019). Wind(ow) of Change: A Systematic Review of Policy Entrepreneurship Characteristics and Strategies. Policy Studies Journal.

doi: https://doi.org/10.1111/psj.12339

Flyvbjerg, B. (2014). What You Should Know About Megaprojects and Why: An Overview. Project Management Journal, 45(2), 6-19.

Gerring, J. (2004). What Is a Case Study and What Is It Good for? American Political Science Review, 98(2), 341-54.

Griggs, S., \& Howarth, D. (2018). So Close, But So Far? The Davies Commission and the Contested Politics of UK Airport Expansion. The Political Quarterly, 89(3), 427-33.

Guldbrandsson, K., \& Fossum, B. (2009). An Exploration of the Theoretical Concepts Policy Windows and Policy Entrepreneurs at the Swedish Public Health Arena.Health Promotion International, 24(4), 434-444.

Hallonsten, O., \& Silander, C. (2012). Commissioning the University of Excellence: Swedish Research Policy and New Public Research Funding Programmes. Quality in Higher Education, 18(3), 367-381.

Herweg, N. (2016). Clarifying the Concept of Policy-Communities in the Multiple-Streams Framework. In R. Zohlnhöfer \& F. W. Rüb (Eds.), Decision-Making Under Ambiguity and Time Constraints: Assessing the Multiple-Streams Framework. Colchester: ECPR, 125-145.

Hinterleitner, M. (2018). Salami Tactics and the Implementation of Large-Scale Public Projects. Journal of European Public Policy.

doi: https://doi.org/10.1080/13501763.2018.1544654

Keeler, J. (1993). Opening the Window for Reform: Mandates, Crises, and Extraordinary PolicyMaking. Comparative Political Studies, 25(4), 433-486.

Kingdon, J. W. (1984). Agendas, Alternatives and Public Policies. Boston, MA: Little, Brown \& Co.

March, J. G., \& Olsen, J. P. (1976). Ambiguity and Choice in Organizations. Bergen: Universitetsforlaget.

March, J. G. (1994). A Primer on Decision Making. New York, NY: Free Press.

Meijerink, S., \& Huitema, D. (2010). Policy Entrepreneurs and Change Strategies: Lessons from Sixteen Case Studies of Water Transitions Around the Globe. Ecology and Society, 15(2), p.21.

Miller, R., \& Lessard, R. D. (2008). Evolving Strategy: Risk Management and the Shaping of MegaProjects. In H. Priemus, B. Flyvbjerg, \& B. Van Wee (Eds.), Decision-Making on Mega-Projects (pp.45172) Cheltenham: Edward Elgar.

Mintrom, M., \& Norman, P. (2009). Policy Entrepreneurship and Policy Change. Policy Studies Journal, 37(4), 649-667.

Mintrom, M. (2013). Policy Entrepreneurs and Controversial Science: Governing Human Embryonic Stem Cell Research. Journal of European Public Policy, 20(3), 442-457.

Morris, Z. S. (2009). The Truth About Interviewing Elites. Politics, 29(3), 209-217.

Oborn, E., Barrett, M., \& Exworthy, M. (2011). Policy Entrepreneurship in the Development of Public Sector Strategy: The Case of London Health Reform. Public Administration, 89(2), 325-344. 
Olsen, J. P. (1983). Organized Democracy: Political Institutions in a Welfare State: The Case of Norway. Bergen: Universitetsforlaget.

Ranga, M., \& Etzkowitz, H. (2013). Triple Helix Systems: An Analytical Framework for Innovation Policy and Practice in the Knowledge Society. Industry and Higher Education, 27, 237-262.

Reimer, I., \& Saerbeck, B. (2017). Policy entrepreneurs in national climate change policy processes. Environment and Planning C: Politics and Space, 35(8), 1456-1470.

Saetren, H. (2016a). From controversial policy idea to successful program implementation: the role of the policy entrepreneur, manipulation strategy, program design, institutions and open policy windows in relocating Norwegian central agencies. Policy Sciences, 49, 71-88.

Saetren, H. (2016b). Lost in Translation: Re-Conceptualising the Multiple-Streams Framework Back to Its Source of Inspiration. In R. Zohlnhöfer \& F. W. Rüb (Eds.), Decision-Making Under Ambiguity and Time Constraints: Assessing the Multiple-Streams Framework (pp.21-34). Colchester: ECPR.

Salet, M., Bertolini, L., \& Giezen, M. (2013). Complexity and Uncertainty: Problem or Asset in Decision Making of Mega Infrastructure Projects? International Journal of Urban and Regional Research, 37(6), 1984-2000.

Schattschneider, E. E. (1975). The Semisovereign People: A Realist's View of Democracy in America. Boston, MA: Wadsworth.

Spohr, F. (2016). Explaining Path Dependency and Deviation by Combining Multiple Streams Framework and Historical Institutionalism: A Comparative Analysis of German and Swedish Labor Market Policies. Journal of Comparative Policy Analysis, 18(3), 257-272.

Weick, K. (1979). The social psychology of organizing. New York, NY: Newbery Award Records.

Wolf, E. \& Van Dooren, W. (2017). How Policies Become Contested: A Spiral of Imagination and Evidence in a Large Infrastructure Project. Policy Sciences, 50(3), 449-468.

Zahariadis, N. (2003). Ambiguity and Choice in Public Policy: Political Decision Making in Modern Democracies. Washington, DC: Georgetown University Press.

Zahariadis, N. (2016a). Bounded Rationality and Garbage Can Models of Policy-Making. In P. Zittoun \& B. G. Peters (Eds.), Contemporary Approaches to Public Policy. London: Palgrave, 155-174.

Zahariadis, N. (2016b). Delphic Oracles: Ambiguity, Institutions, and Multiple Streams. Policy Sciences, 49(1), 3-12.

Zohlnhöfer, R., Herweg, N., \& Rüb, F. W. (2015). Theoretically refining the multiple streams framework: An introduction. European Journal of Political Research, 54, 412-418.

Zohlnhöfer, R., \& Rüb, F. W. (2016) Introduction. In R. Zohlnhöfer and F. W. Rüb (Eds.), DecisionMaking Under Ambiguity and Time Constraints: Assessing the Multiple-Streams Framework (pp.1-18). Colchester: ECPR.

\section{Documents}

Karolinska hospital (2002). Förslag till förnyelse av Karolinska sjukhuset. LOC 0006-1049

Locum (2002). Fastighetsutvecklingsplan för Karolinska sjukhusområdet. Varv 2, remissutgåva april 2002.

Stockholm County Council (2001). Letter from Ralph Lédel, November 28, 2001. LS 0111-0650.

Stockholm County Council (2002). SNUS-utredningen. 
Stockholm County Council (2004). 3 S-utredningen. Den framtida närsjukvården.

Stockholm County Council (2006). Nya Karolinska Solna, Uppdragsramar för projektprogram.

SOU 2015:98. Träning ger färdighet: koncentrera vården för patientens bästa. Swedish Official Governmental Report.

\section{Interviews}

\begin{tabular}{|c|c|c|}
\hline id-number & $\begin{array}{l}\text { Interviewee's position during the early stages of the } \\
\text { NKS process }\end{array}$ & Interview date \\
\hline IP 1 & Medical advisor & 2017-10-18 \\
\hline IP 2 & SCC politician, Liberal Party & 2017-12-13 \\
\hline IP 3 & Deputy administrative director, SCC & 2017-10-13 \\
\hline IP 4 & President of Karolinska Institutet (KI) & 2017-10-31 \\
\hline IP 5 & CEO, Locum (SCC property company) & 2017-10-09 \\
\hline IP 6 & Manager, Locum (SCC property company) & 2017-11-16 \\
\hline IP 7 & Chair of the medical union, Huddinge Hospital & 2017-10-11 \\
\hline IP 8 & Deputy health director, SCC & 2017-11-02 \\
\hline IP 9 & Deputy hospital director, Karolinska Hospital & 2017-11-09 \\
\hline IP 10 & Director of finance, SCC & $2017-10-30$ \\
\hline IP 11 & Manager, Karolinska Hospital & 2017-10-05 \\
\hline IP 12 & Professor, Karolinska Institutet (KI) & 2017-12-12 \\
\hline IP 13 & SCC politician, Christian Democratic Party & 2017-11-13 \\
\hline IP 14 & Administrative Director, SCC & $2017-10-30$ \\
\hline IP 15 & SCC politician, Social Democratic Party & 2018-01-16 \\
\hline IP 16 & SCC politician, Moderate Party & 2018-01-17 \\
\hline IP 17 & SCC politician, Social Democratic Party & 2018-02-19 \\
\hline IP 18 & Manager, SCC & 2018-02-27 \\
\hline
\end{tabular}

